\title{
REKAYASA PERANGKAT LUNAK RESEP KULINER NUSANTARA BERBASIS ANDROID
}

\author{
Shinta Sari Dewi \\ Program Studi Informatika, Fakultas Teknik dan Ilmu Komputer, Universitas Indraprasta PGRI \\ Jalan Raya Tengah No 80, Kelurahan Gedong, Pasar Rebo, Jakarta Timur \\ shinta.sari14@gmail.com
}

\begin{abstract}
Abstrak
Masakan Indonesia salah satu bentuk tradisi kuliner yang mencerminkan suatu keanekaragaman budaya yang ada di tanah Indonesia. Secara umum kuliner yang ada di nusantara memiliki cita rasa yang beragam dan kaya akan bumbu yang berasal dari rempah-rempah yang ada di bumi nusantara. Dengan berkembangnya teknologi, informasi dapat diakses dengan mudah saat ini. Begitu pula dengan informasi resep masakan. Sayangnya kebanyakan resep masakan yang beredar merupakan resep yang berasal dari mancanegara. Sehingga pengetahuan akan kuliner di tanah air sendiri semakin menghilang dan terlupakan. Oleh sebab ini peneliti ingin membuat sebuah aplikasi yang dapat memudahkan para pengguna untuk melihat resep masakan nusantara tanpa harus bersusah payah membawa buku resep kemana-mana. Tujuan dari penelitian ini adalah untuk menciptakan sebuah media berupa aplikasi Android yang berisi katalog resep-resep masakan yang berasal dari penjuru Indonesia. Metode penelitian yang digunakan adalah grounded research yaitu suatu metode penelitian berdasarkan pada fakta dan menggunakan analisis perbandingan dengan tujuan mengadakan generalisasi empiris, menetapkan konsep, membuktikan teori, mengembangkan teori, pengumpulan dan analisis data dalam waktu yang bersamaan. Dalam hal ini peneliti menarik kesimpulan bahwa hasil yang didapatkan peneliti adalah terciptanya sebuah aplikasi resep kuliner nusantara yang berbasis Android.
\end{abstract}

Kata kunci : Sistem Informasi, Resep Masakan, Android.

\begin{abstract}
Indonesian cuisine is one form of culinary tradition that reflects a diversity of culture in the land of Indonesia. In general, culinary in the archipelago has a variety of flavors and rich in spices derived from the spices that exist in the archipelago Earth. With the development of technology, information can be accessed easily at this time. Similarly, the cooking recipe information. Unfortunately, most of the recipes in circulation are foreign recipes. So the knowledge of culinary in the homeland itself is increasingly disappearing and forgotten. Because of this, researchers want to create an application that can make it easier for users to see archipelago cuisine recipes without having to bother carrying a recipe book anywhere.. The purpose of this research is to create an Android application that contains a catalogue of cooking recipes from across Indonesia. The research method used is grounded research is a method of research based on facts and use comparative analysis with the aim of conducting empirical generalizations, establishing concepts, proving theories, developing theories, collecting and analyzing data at the same time. In this case the researcher draws the conclusion that the results obtained by the researcher is the creation of an application culinary recipes archipelago based on Android.
\end{abstract}

Keywords : Information System, Cooking Recipes, Android.

\section{PENDAHULUAN}

Masakan Indonesia adalah salah satu bentuk tradisi kuliner yang mana mencerminkan suatu keanekaragaman budaya yang ada di tanah Indonesia. Secara umum kuliner yang ada di nusantara memiliki cita rasa yang beragam dan kaya akan bumbu yang berasal dari rempah-rempah yang ada di bumi nusantara. Dengan berkembangnya teknologi, informasi dapat diakses dengan mudah saat ini. Begitu pula dengan informasi resep masakan. Sayangnya kebanyakan resep masakan yang beredar merupakan resep yang berasal dari mancanegara. Sehingga pengetahuan akan kuliner di tanah air sendiri semakin menghilang dan terlupakan. Inilah mengapa peneliti ingin membuat sebuah aplikasi yang dapat memudahkan para pengguna untuk melihat resep masakan nusantara tanpa harus bersusah payah membawa buku resep kemana-mana. Menurut (Sutabri, 2012), aplikasi adalah suatu alat yang memiliki fungsi khusus berdasarkan kemampuan yang dimilikinya untuk membantu melakukan suatu pekerjaan bagi penggunanya. 
Tujuan dari penelitian ini adalah untuk merancang sebuah media berupa aplikasi Android yang berisi katalog resep-resep masakan yang berasal dari penjuru Indonesia. Menurut (Anggraeni \& Kustijono, 2013), Android merupakan sistem operasi yang paling diminati di masyarakat karena memiliki kelebihan seperti sifat open source yang memberikan kebebasan para pengembang untuk menciptakan aplikasi. Untuk saat ini aplikasi Android merupakan sistem yang digemari oleh masyarakat. Oleh karena itu, dengan berkembangnya penggunaan Android, maka peneliti memutuskan membuat sebuah aplikasi resep kuliner agar memudahkan para pengguna Android untuk mengakses katalog resep masakan nusantara secara efisien.

\section{PENELITIAN RELEVAN}

Penelitian relevan yang dilakukan oleh (Sutabri1 \& Zaeni, 2013) Perancangan dan Implementasi Aplikasi Ensiklopedia Resep Masakan Khas Kuningan Jawa Barat Berbasis Android. Dalam mengembangkan aplikasinya menggunakan metode penelitian Rapid Application Development yaitu teknik dalam pemrograman untuk membantu aplikasi memungkinkan bekerja secara cepat. Yang dihasilkan dalam penelitian ini adalah sebuah aplikasi dengan judul Ensiklopedia Resep Masakan yang dipusatkan pada kuliner khas dari daerah Kuningan Jawa Barat. Sebagai editor bahasa pemrograman aplikasi dirancang menggunakan bahasa pemrogrman java android, XML, HTML sedangkan untuk compiler bahasa pemrograman menggunakan Eclipse IDE. Dan aplikasi ini dapat berjalan dengan baik pada android versi 4.1 - 5.0.

Penelitian relevan yang dilakukan oleh (Chandra, 2016) Perancangan Aplikasi Resep Masakan Tradisional Indonesia Menggunakan Pendekatan Agile Process Dengan Model Extreme Programming Berbasis Android. Dalam menggembangkan aplikasinya menggunakan metode penelitian kajian pustaka dengan mengumpulkan data dari berbagai nara sumber buku, serta melakukan observasi dengan mengamati secara langsung ke lapangan menemui beberapa narasumber yang dipercaya. Aplikasi dirancang dengan model Extreme Programming dalam meningkatkan fleksibilitas melalui teknik pengembangan perangkat lunak. Penelitian ini bertujuan agar masyarakat mengenal kembali masakan tradisional di bumi nusantara. Dan aplikasi ini dapat diakses dengan baik pada tablet PC dan Android.

\section{METODE PENELITIAN}

Metode penelitian adalah beberapa langkah yang ditempuh dengan mengumpulkan berbagai informasi berupa data untuk pemecahan masalah dan menemukan jawaban dari masalah yang terjadi. Peneliti dalam penelitiannya menggunakan metode grounded research. Menurut (Sugiyono, 2014), metode grounded research yaitu suatu metode penelitian berdasarkan pada fakta dan menggunakan analisis perbandingan dengan tujuan mengadakan generalisasi empiris, menetapkan konsep, membuktikan teori, mengembangkan teori, pengumpulan dan analisis data dalam waktu yang bersamaan. Dalam penelitian, adapun langkah-langkah yang dilakukan untuk mengembangkan sistem dalam penyusunan ini adalah metode dalam pengumpulan data, yang peneliti melakukan studi pustaka, yaitu mencari bahan-bahan yang relevan dengan objek yang akan diteliti. Pengumpulan data dari kutipan buku-buku, situs-situs internet, dan hasil laporan dari bahan lain yang berhubungan dengan Android. Lalu selanjutnya menganalisa kebutuhan aplikasi dengan cara melakukan observasi terhadap beberapa website resep masakan yang ada. Selanjutnya dirancanglah dan diimplementasikan aplikasi resep masakan yang dikembangkan memakai android studio dan bahasa pemrograman java. Kemudian dilakukan pengujian terhadap sistem tersebut sampai semua tahap selesai. Dilanjutkan dengan pemeliharaan sistem yang telah siap digunakan.

\section{HASIL DAN PEMBAHASAN}

\section{Analisa Permasalahan}

Masakan Indonesia adalah salah satu bentuk tradisi kuliner yang mana mencerminkan suatu keanekaragaman budaya yang ada di tanah Indonesia. Secara umum kuliner yang ada di nusantara memiliki cita rasa yang beragam dan kaya akan bumbu yang berasal dari rempah-rempah yang ada di bumi nusantara. Dengan berkembangnya teknologi, informasi dapat diakses dengan mudah saat ini. Begitu pula dengan informasi resep masakan. Sayangnya kebanyakan resep masakan yang beredar merupakan resep yang berasal dari mancanegara. Sehingga pengetahuan akan kuliner di tanah air sendiri semakin menghilang dan terlupakan. 


\section{Alternatif Penyelesaian Masalah}

Melihat masalah yang ada, banyak masyarakat yang ingin membuat masakan nusantara dan mencari resep-resep masakan nusantara, namun yang lebih praktis. Inilah mengapa peneliti ingin membuat sebuah aplikasi yang dapat memudahkan para pengguna untuk melihat resep masakan nusantara tanpa harus bersusah payah membawa buku resep kemana-mana. Maka dari itu, peneliti menciptakan sebuah media berupa aplikasi Android yang berisi katalog resep-resep masakan yang berasal dari penjuru Indonesia agar memberikan solusi untuk masalah ini karena tersedianya berbagai macam resep masakan nusantara dalam aplikasi Android.

\section{Flowchart}

Berikut adalah flowchart yang dihasilkan dalam pengembangan sistem, yang berfokus pada menu utama.

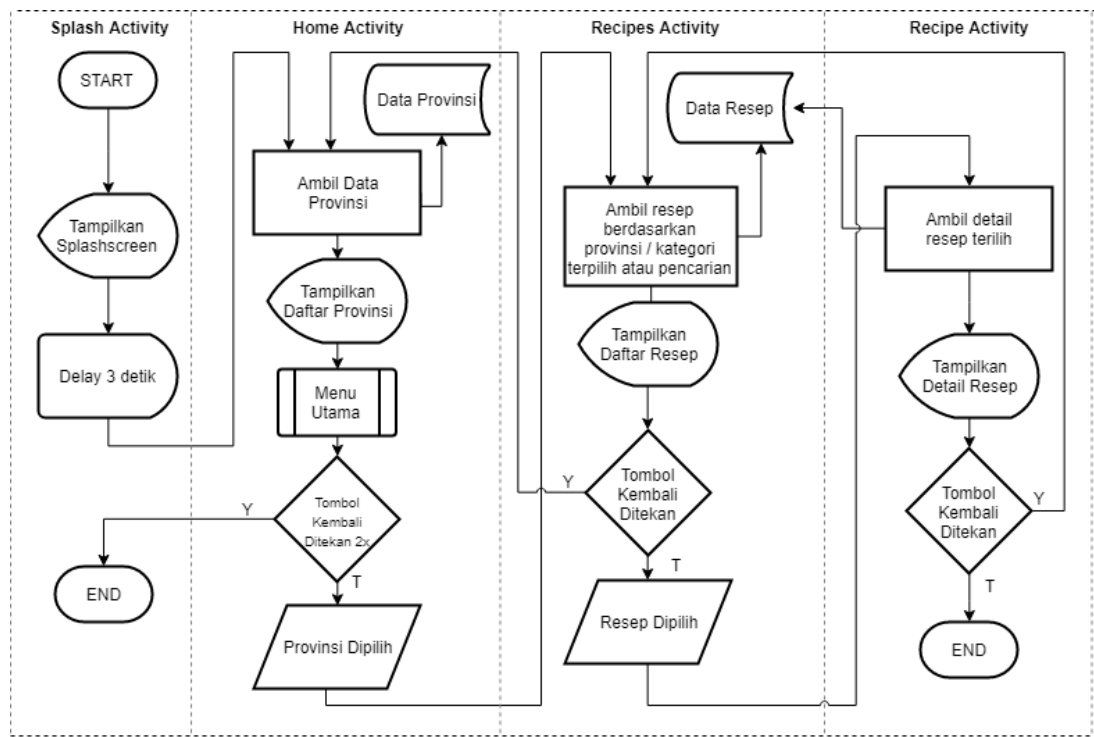

Gambar 1. Flowchart Aplikasi

Aplikasi saat pertama kali dipilih pengguna maka akan muncul tampilan splashscreen. Lalu akan tampil pada halaman menu utama, yang mana jika pengguna memilih tombol propinsi, maka akan tampil 34 propinsi yang ada di Indonesia. Setelah melanjutkan, pengguna memilih salah satu propinsi yang diinginkan, maka akan tampil beberapa nama resep masakan yang berasal dari propinsi tersebut. Setelah itu tekan tombol nama resep yang diingkan, maka akan tampil resep masakan tersebut beserta nama bahan dan cara pembuatan.

\section{Rancangan Layar Aplikasi}

Berikut adalah gambar rancangan dari splashscreen yang akan ditampilkan dalam aplikasi.

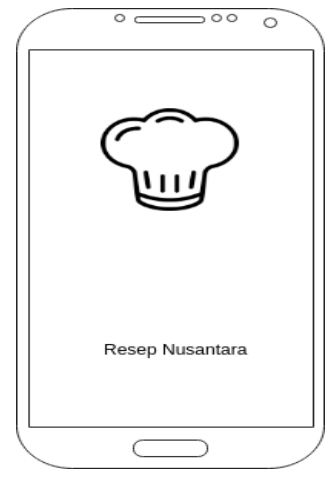

Gambar 2. Rancangan Tampilan Splash Screen 


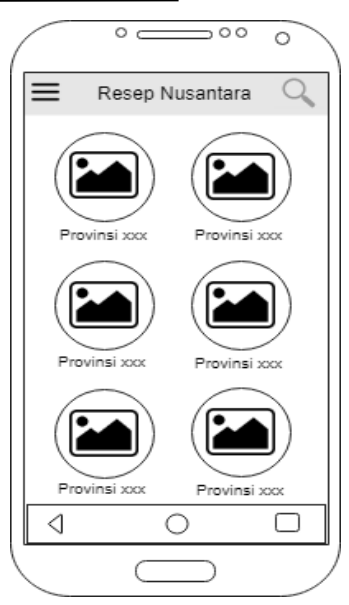

Gambar 3. Rancangan Tampilan Menu Utama

Berikut adalah tampilan rancangan dari menu utama aplikasi resep masakan yang menampikan beberapa tombol nama propinsi, tombol pencarian, dan menu kategori.

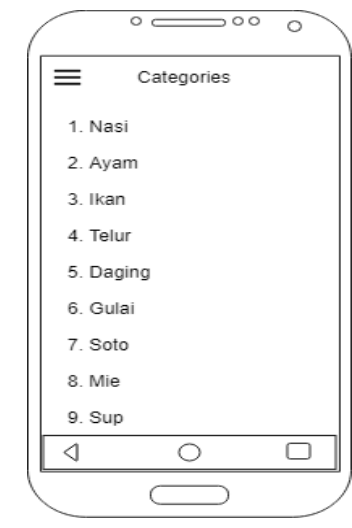

Gambar 4. Rancangan Tampilan Menu Kategori

Jika tombol pencarian di klik maka akan tampil beberapa nama bahan makanan yang sudah dikategorikan.

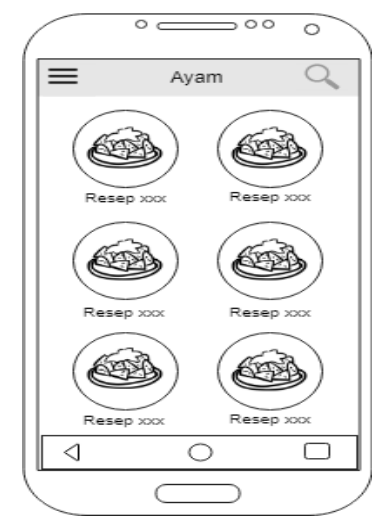

Gambar 5. Rancangan Tampilan Search

Tampilan rancangan menu pencarian, yang mana jika kita mencari nama makanan yang diinginkan ada, maka akan muncul nama resep nya. 


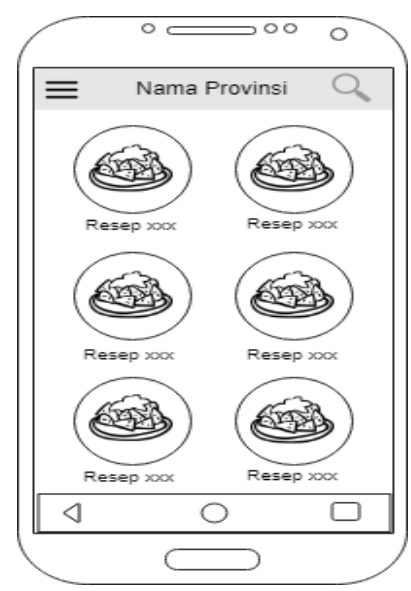

Gambar 6. Rancangan Tampilan Menu Daftar Resep Masakan

Tampilan rancangan menu daftar nama resep masakan, yang mana berisi resep dari berbagai propinsi yang ada di Indonesia.

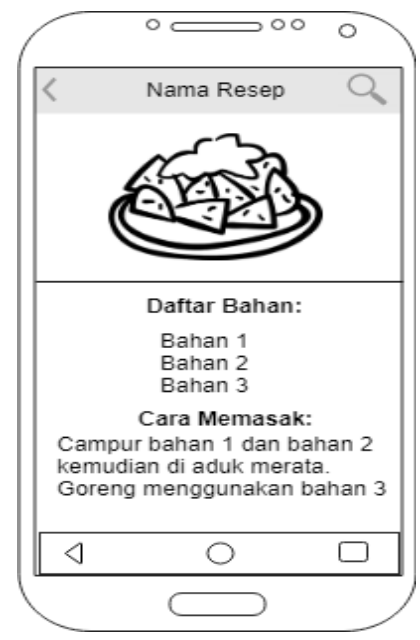

Gambar 7. Rancangan Tampilan Resep Masakan

Rancangan tampilan isi dari resep masakan, berupa bahan dan cara pembuatannya.

\section{Tampilan Aplikasi}

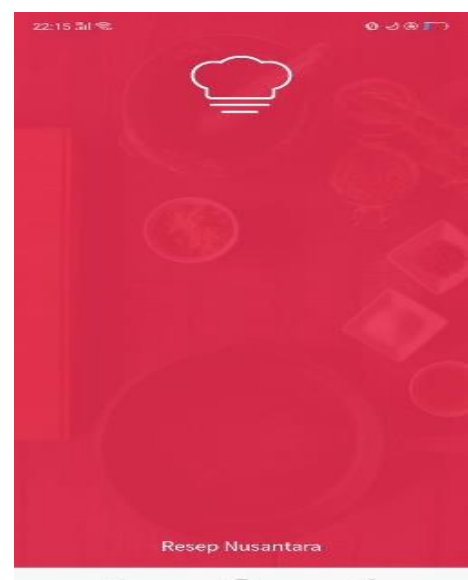

Gambar 8. Tampilan Splash Screen

Tampilan Splash Screen adalah tampilan saat aplikasi pertama dijalankan 


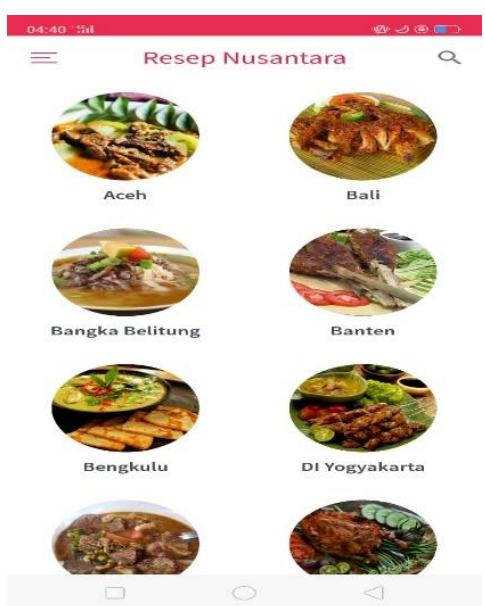

Gambar 9. Tampilan Menu Utama

Tampilan menu utama menampilkan beberapa tombol nama propinsi, tombol pencarian, dan menu kategori.

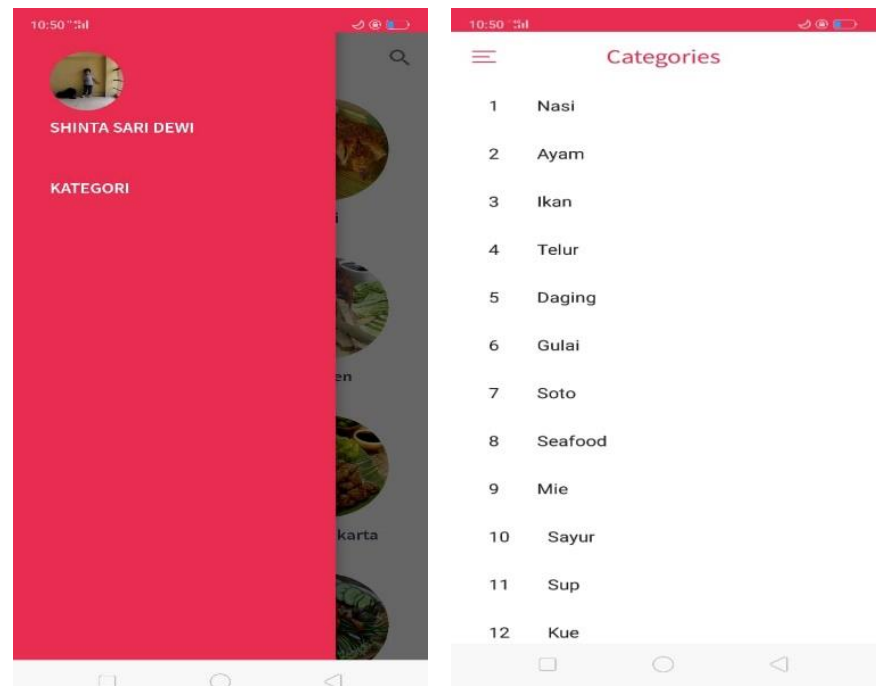

Gambar 10. Tampilan Menu Kategori

Pada tampilan menu kategori terdapat beberapa nama bahan makanan yang sudah dikategorikan.

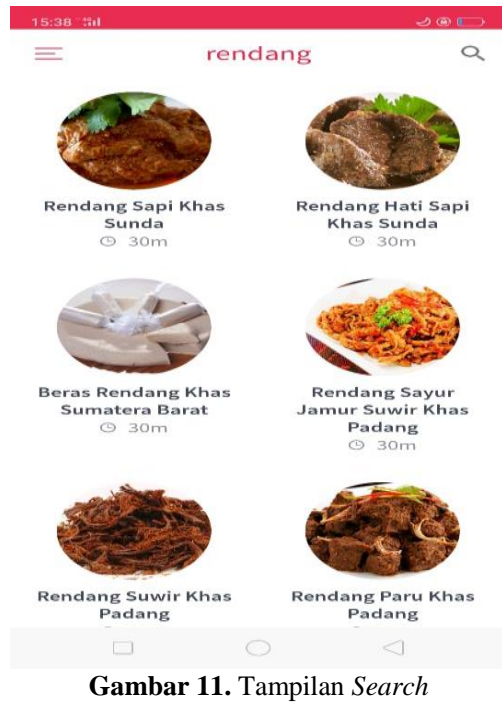


Tampilan menu pencarian digunakan jika kita mencari nama makanan yang diinginkan ada, maka akan muncul nama resep nya.

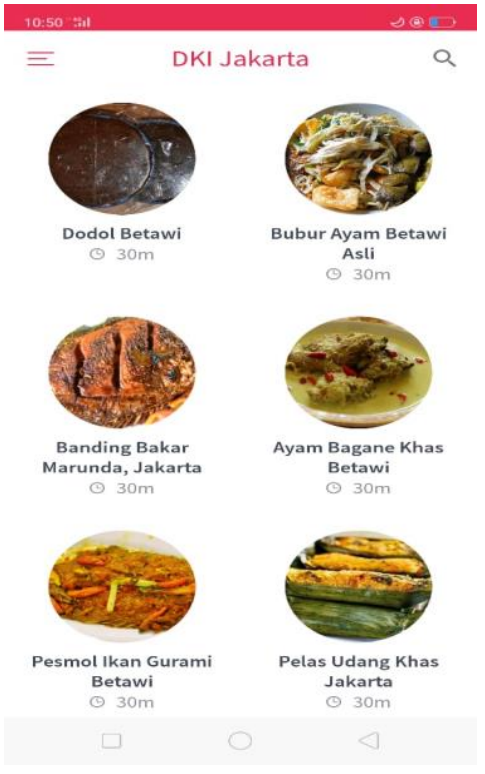

Gambar 12. Tampilan Menu Daftar Resep Masakan

Tampilan daftar nama resep masakan terdiri dari resep dari berbagai propinsi yang ada di Indonesia.

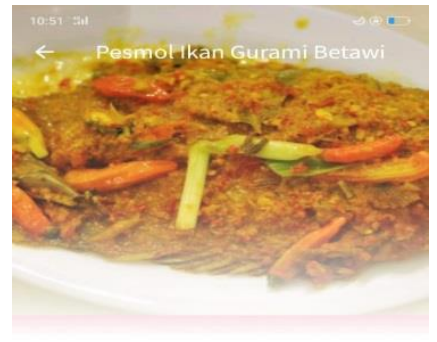

Pesmol Ikan Gurami Betawi (c) 1 h 20

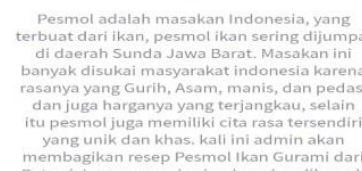

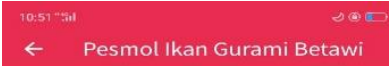

$\leftarrow$ Pesmol Ikan Gurami Betawi

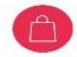

BAHAN-BAHAN

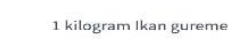

$250 \mathrm{ml}$ air

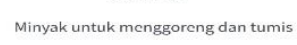

Bumbu-bumbu

1 buah tomat

1 sendok teh air jeruk nipis

10 buah cabai rawit hijau

2 lembar daun jeruk

2 lembar daun salam

1 batang serai

$3 / 4$ sendok teh gula pasir

garam 1 sendok makan

Bumbu halus

\section{Pesmol Ikan Gurami Betawi}

CARA MEMASAK
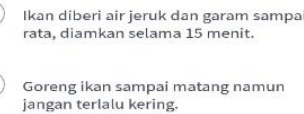
bersama daun jeruk, serai dan salam.
Tambahkan potongan cabai rawit dan

Setelah tumisan layu dan harum, masukan ikan yang sudah digoreng,
tambahkan garam dan gula pasir, lalu tambahkan garam
aduk hingga rata.

\section{Tuangkan air, diamkan sampai bumbu
benar benar, meresap ke dalam iklan.}

Haluskan semua bumbu kemudian tumis

Gambar 13. Tampilan Resep Masakan

Tampilan resep masakan, berupa bahan dan cara pembuatannya

\section{SIMPULAN}

Berdasarkan hasil dari penulisan perancangan Aplikasi Resep Kuliner Nusantara ini diharapkan dapat membantu masyarakat dalam memperoleh berbagai informasi mengenai kuliner yang ada di bumi nusantara ini. Serta menumbuhkan kesadaran masyarakat akan budaya dan tradisi di tanah air yang semakin lama dilupakan. Aplikasi ini terdiri dari 34 propinsi yang ada di Indonesia, dan memiliki beberapa keunggulan diantaranya terdapat menu kategori dan menu pencarian. Aplikasi ini dibuat untuk memudahkan pengguna dalam mengakses informasi melalui Android secara efektif dan mudah. 


\section{DAFTAR PUSTAKA}

Chandra, Y. I. (2016). Perancangan Aplikasi Resep Makanan Tradisional Indonesia Menggunakan Pendekatan Agile Process Dengan Model Extreme Programming Berbasis Android. Seminar Nasional APTIKOM.

Dian Anggraeni, R., \& Kustijono, R. (2013). PENGEMBANGAN MEDIA ANIMASI FISIKA PADA MATERI

CAHAYA DENGAN APLIKASI FLASH BERBASIS ANDROID. Jurnal Penelitian Fisika Dan Aplikasinya (JPFA). https://doi.org/10.26740/jpfa.v3n1.p11-18

Rumbaugh, J. (2010). Unified Modeling Language (UML). In Encyclopedia of Software Engineering. https://doi.org/10.1081/e-ese-120044214

Sugiyono. (2014). Metode penelitian. Metode Penelitian.

Sutabri, T. (2012). Analisis Sistem Informasi. In Analisa Sistem Informasi.

Sutabri1, T., \& Zaeni, F. (2013). PERANCANGAN DAN IMPLEMENTASI APLIKASI ENSIKLOPEDIA RESEP MASAKAN KHAS KUNINGAN JAWA BARAT BERBASIS ANDROID. Journal of Chemical Information and Modeling. https://doi.org/10.1017/CBO9781107415324.004 